\title{
USE OF PRESSURE SPECTRAL MAPS FOR ANALYSIS OF INFLUENCE OF THE PLENUM VOLUME ON THE SURGE IN CENTRIFUGAL BLOWER
}

\author{
Kirill Kabalyk, Grzegorz Liśkiewicz ${ }^{\dagger *}$, \\ Longin Horodko, Władysław Kryłłowicz ${ }^{\dagger}$ \\ Institute of Turbomachinery \\ Łódź University of Technology \\ ul. Wólczańska 219/223 \\ 90 - 924 Łódź, Poland
}

\author{
Matthew Stickland \\ Department of Mechanical \\ and Aerospace Engineering \\ University of Strathclyde \\ 75 Montrose street \\ G1 1XJ Glasgow, Scotland
}

\begin{abstract}
The influence of plenum volume on surge phenomenon in a centrifugal blower was studied by means of quasidynamic analysis. In this procedure, signals were gathered at 5 pressure tappings at 146 different positions of the throttling valve controlling the mass flow rate. Frequency spectra obtained by means of Fourier analysis are combined together in the form of colour maps with frequency as the abscissa and valve position as the ordinate. Such a map provides high-resolution information about spectral structures of pressure signals attained at different mass flow rates. Analysis was conducted at two system configurations characterized by different volumes between the blower and the valve i.e. plenum volume. Research confirmed that in both cases the first disturbances appear in the vicinity of the impeller leading edge in the same position of a throttling valve before the surge. Arising flow structure is characterized by strong and random pressure jumps and does not have any dominating frequency. At further valve closure pressure disturbances propagate towards the volute and at deep surge the strongest peaks are observed at the outlet. The moment of deep surge onset is also independent of the plenum volume, however, a difference is observed in the frequency and amplitude of the main modes. With the higher outlet volume the observed oscillations fit well to the frequency of a Helmholtz resonator while, in the case of the smaller volume, the frequency is higher than the frequency of a corresponding Helmholtz resonator.
\end{abstract}

\footnotetext{
${ }^{\dagger}$ ASME member

* Corresponding author: grzegorz.liskiewicz@p.lodz.pl
}

\section{NOMENCLATURE}

\begin{tabular}{|c|c|}
\hline$A_{c}$ & $\begin{array}{l}\text { compressor duct characteristic } \\
\text { area }\end{array}$ \\
\hline$a$ & speed of sound \\
\hline$b$ & channel height \\
\hline $\mathrm{BPF}$ & blade passing frequency \\
\hline$D$ & diameter \\
\hline$f$ & frequency \\
\hline$K_{T}$ & throttle coefficient \\
\hline$k$ & specific heat capacity ratio \\
\hline$L$ & length \\
\hline$L_{c}$ & $\begin{array}{l}\text { compressor duct characteristic } \\
\text { length }\end{array}$ \\
\hline LP & long pipe \\
\hline$M_{\mathrm{u}}=\frac{u_{\text {imp-out }}}{\sqrt{k R T_{\text {in }}^{*}}}$ & specific Mach number \\
\hline$n$ & rotor rotational speed \\
\hline$R$ & air gas constant \\
\hline SP & short pipe \\
\hline$T$ & temperature \\
\hline TOA & throttle opening area \\
\hline$u_{\text {imp-out }}=\frac{2 \pi n}{60} D_{\text {imp-out }}$ & impeller tip speed \\
\hline$V$ & volume \\
\hline$z$ & number of blades \\
\hline$\beta_{\text {bl-imp-out }}$ & $\begin{array}{l}\text { blade sweep angle at impeller } \\
\text { outlet }\end{array}$ \\
\hline$\Delta \mathrm{p}$ & pressure fluctuation amplitude \\
\hline$\delta$ & gap between blade and shroud \\
\hline$v=\frac{D_{h}}{D_{\text {imp-out }}}$ & impeller hub ratio \\
\hline
\end{tabular}




\section{SUBSCRIPTS}

$\begin{array}{ll}\text { bl } & \text { blade } \\ c & \text { compressor } \\ h & \text { hub } \\ H & \text { Helmholtz } \\ \text { imp } & \text { impeller } \\ \text { in } & \text { inlet } \\ \text { long } & \text { long outlet pipe } \\ m & \text { meridional } \\ \text { out } & \text { outlet } \\ p & \text { plenum } \\ \text { rot } & \text { rotor } \\ s & \text { shroud, surge } \\ \text { short } & \text { short outlet pipe } \\ \text { VLD } & \text { vaneless diffuser } \\ \text { vol } & \text { volute }\end{array}$

\section{INTRODUCTION}

\subsection{State of the art}

Unsteady flow phenomena within centrifugal compressors have remained an object of interest for designers, manufacturers and scientists for almost 60 years. The reason for this lies in the desire to make the machine operate safely and efficiently. The work considered as an initial milestone in the field is the work by Emmons et al. [1]. The authors utilized hot-wire probes connected to the static pressure taps. The measurements were carried out after the impeller inducer and at the vaneless diffuser outlet. As a result, the instantaneous pressure signal was recorded and analyzed. Finally, four stages of unstable operation were defined:

stable operation, when the pulsation amplitude was almost null;

mild surge, when the amplitude didn't exceed $10 \%$ of maximum pressure rise;

intermediate phase, with relatively stable flow;

deep surge, when the pressure fluctuations exceeded $30 \%$ of the maximum pressure rise.

Up to now, a vast number of research articles and theses were published describing the application of experimental, numerical and mathematical methods to study and forecast the unsteady phenomena in axial and centrifugal compression systems [2-5]. As a result, the majority of phenomena have been named and classified [6,7]. Moreover, quick and experimentally verified mathematical models [8-11] were created to predict the machine behavior during its steady or unsteady operation. In contemporary anti-surge systems high-frequency semiconductor transducers might be used to control and monitor the machine aerodynamic stability during operation [12].

However, not all the problems connected to the topic are yet resolved. For instance, it is not well known how the network volume changes the amplitude and frequency of flow pressure fluctuations inside the installation. The number of publications regarding this topic is relatively low. Fink et al. [13] studied the behavior of a single-stage high-speed compressor during surge and at its onset. Two different outlet downstream volumes were examined. Only a larger one with a plenum chamber was utilized to investigate surge. A smaller one with a throttle installed right after the volute was used for a time-averaged analysis. It was shown that the pressure and velocity pulsations during deep surge are likely to decline in amplitude and grow in frequency as the outlet volume was decreased. A system without plenum was observed to operate without falling into deep surge right up to the total shutoff. However, the phenomena known as rotating stall and mild surge were registered within this system.

Koyama et al. [14] investigated a similar problem, although a low-speed medium-size installation was analyzed. Three outlet plenums were examined with the ratio of plenum to compressor duct volumes equal to 0.07 , 0.92 and 5.20. The instantaneous pressure signal was recorded at the impeller inlet, impeller outlet and plenum inlet. Fourier signal analysis was applied to process the raw signal data. The test series didn't identify any serious difference in measurement results within the compressor duct (inducer, vaneless diffuser). The dominating pressure pulsation frequencies during rotating stall and surge were equal to $30 \mathrm{~Hz}$ (inducer) and $47 \mathrm{~Hz}$ (vaneless diffuser) regardless of the outlet volume. However, the higher outlet volumes induced higher values of pulsation amplitude. Gauges installed at the plenum inlet recorded a triple drop of frequency and magnitude of the pressure oscillations between low and medium plenum volumes. A further rise in plenum size resulted in an amplitude rise but didn't influence the surge frequency.

\subsection{The scope of the work}

This paper describes an investigation of the influence of compressor downstream volume on machine unsteady performance by means of pressure spectral maps. Such maps have proven to be an efficient way of presenting compressor performance throughout a wide range of working conditions. They are obtained in a "quasidynamic" procedure described in section 2.2. Results are presented in the form of colour maps with frequency as the abscissa and the throttle valve position as the ordinate. This provides high-resolution information about spectral structures of pressure signals attained at different mass flow rates. Secondly, the impeller tip speed chosen for the experiment was $u_{\text {imp-out }}=103,7 \mathrm{~m} / \mathrm{s}$ which is much closer to the values attained in industrial compressors than that in [14].

The aim of this study was to check how the compressor plenum volume influences the pressure pulsation spectra at different locations. Moreover, the authors have analyzed how experimental results fit to the fundamental model of Helmholtz resonator.

\subsection{Helmholtz resonance in compressing units}

According to the method proposed by Moore and Greitzer [8] a turbo compressor installation might be 
treated as a system shown in Fig. 1. It consists of three major elements:

- compressor duct, which includes all the ducts upstream and downstream of the impeller and is characterised by area $A_{c}$ and length $L_{c}$;

- plenum, that includes the network that the compressor works with (characterised by plenum volume $V_{p}$ );

- throttle, used to control the mass flow rate (according to [8] characterised by throttle coefficient $K_{T}$ ).

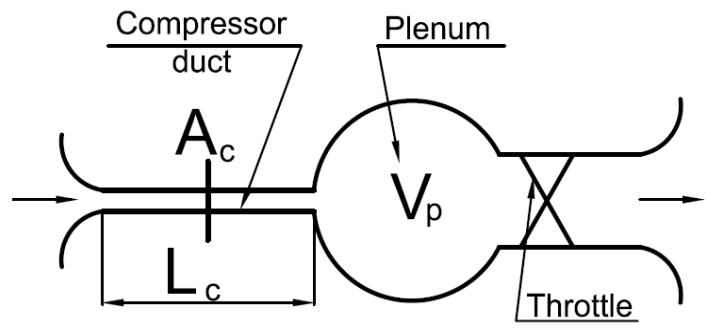

\section{Figure 1. Compression system elementary scheme according to Greitzer. [8].}

At surge pressure starts to oscillate within the compressor setting. In such circumstances the volume $V_{p}$ can play the role of a Helmholtz resonator such as when one blows across the top of an empty bottle [13]. The natural frequency of a Helmholtz resonator is given as:

$$
f_{h}=\frac{a}{2 \pi} \sqrt{\frac{A_{c}}{V_{p} L_{c}}}
$$

Apart from the required simplification of the system, this formula has been proven to provide a reasonable prediction of the frequency of non-stable phenomena [13]. Therefore, the second task of the work was to compare the resonance frequencies calculated with eq. (1) to the

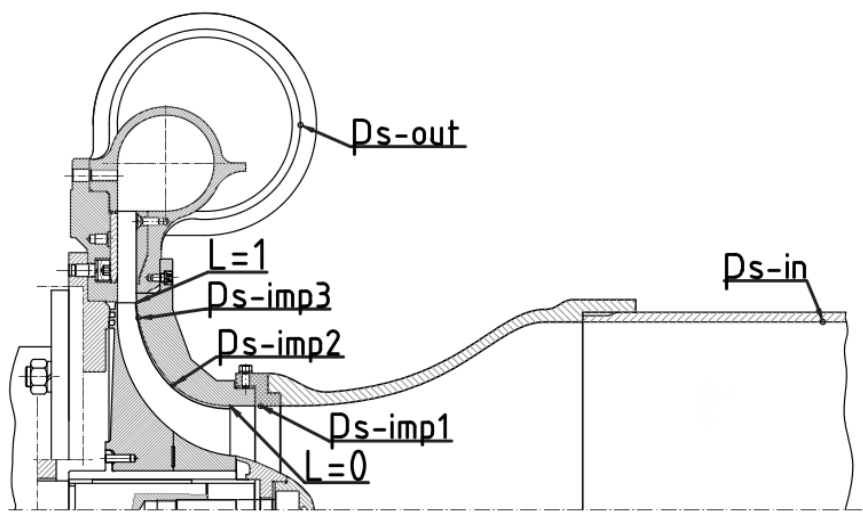

(a) corresponding dominating surge frequencies obtained experimentally.

\section{THE CONCEPT OF EXPERIMENTS}

\subsection{Test stand description}

A single stage centrifugal blower DP1.12 designed at the Institute of Turbomachinery, Lodz University of Technology was the object of investigation. The test rig is described in detail by Magiera [16]. Fig. 2 illustrates its cross-section. The measurements were carried out over the whole operational range of the machine at the rotor rotational speed of $n=6000 \mathrm{rpm}\left(f_{\text {rot }}=100 \mathrm{~Hz}\right)$, which corresponds to the specific Mach number of $M_{\mathrm{u}}=0.33$.

The flow entered the stage through the inlet pipe of 300 $\mathrm{mm}$ in diameter. It was connected to the compressor casing by a Witoszynski nozzle [17]. Shroud internal diameter was equal to $D_{\text {s-in }}=165,6 \mathrm{~mm}$ and the inlet blade height was $b_{\text {imp-in }}=40 \mathrm{~mm}$. The unshrouded impeller had 23 blades. Each blade consisted of an axial inducer and a radial vane with outlet angle $\beta_{\text {bl-imp-out }}=90^{\circ}$. The gap between the blade and casing was $\delta_{\text {imp }}=0,8 \mathrm{~mm}$. The impeller outlet diameter was $D_{\text {imp-out }}=330,2 \mathrm{~mm}$, outlet blade height $b_{\text {imp-out }}=15 \mathrm{~mm}$ and the hub ratio $v=0,26$. The meridional blade shroud coordinate $L$ had its origin at the leading edge $(L=0)$ and ends at the trailing edge ( $L=1$ ). The total blade outline at the shroud was equal to $134 \mathrm{~mm}$. The vaneless diffuser had outer diameter of $D_{\text {VLD-out }}=470 \mathrm{~mm}$ and constant height. It was followed by an external overhung volute that ended at the stage setting. The volute was connected to the outlet pipe with internal diameter of $D_{\text {votout }}=150 \mathrm{~mm}$. As shown in Fig. 2(b), the "plenum" was divided into three segments: vertical pipe (seg. 1), right angled elbow (seg. 2) and horizontal pipe (seg. 3).

The alteration of the plenum volume was realized by changing the length of the segment 3 . In this work, two different lengths are considered:

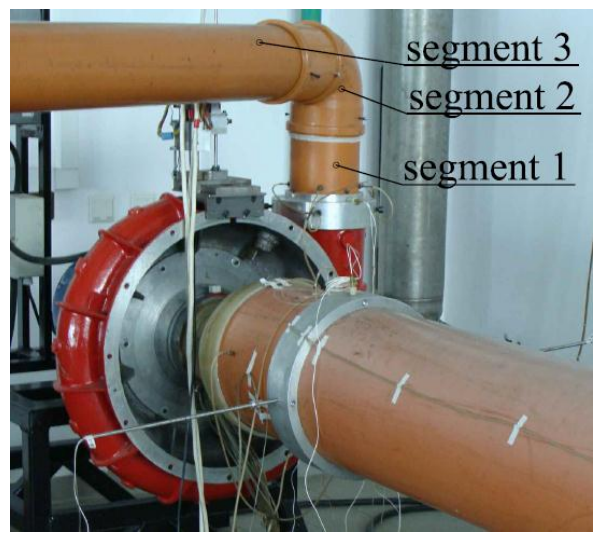

(b) 
- short pipe (SP) with the length of $L_{\text {short }}=755 \mathrm{~mm}$;

- long pipe (LP) with the length of $L_{\text {long }}=3460 \mathrm{~mm}$.

At the outlet of the pipe the throttle valve was installed to control the machine mass flow rate. The outlet plenum volume was computed as sum of volumes of all pipe segments, volute and diffuser and was equal to:

- $V_{\text {short }}=4.35 \cdot 10^{-2} \mathrm{~m}^{3}$ in SP case;

- $V_{\text {long }}=9.68 \cdot 10^{-2} m^{3}$ in LP case.

\subsection{The quasi-dynamic analysis concept}

The static pressure signals were captured by Kulite transducers installed as shown in Fig. 2(a). The static pressure signals were recorded before the nozzle $\left(p_{\text {s-in }}\right)$, at the impeller inlet $\left(p_{\text {s-imp } 1}, L=-0.2\right)$, at the impeller middle part $\left(p_{\text {s-imp } 2}, L=0.4\right)$, at the impeller outlet ( $p_{\text {s-imp3 }}, L=0.9$ ) and at the volute outlet ( $p_{\text {s-out }}$ ).

The main aim of applied approach was to find a way of measuring the progressive onset of unstable phenomena by a very slow change of the throttling valve. The position of the throttling valve was characterized by a nondimensional parameter named as Throttling Opening Area, or TOA. This parameter simply expresses the percentage of the pipe area that was left open at the system outlet. Each measurement was conducted at constant TOA and contained $2^{21}=2097152$ samples gathered at a frequency of $100 \mathrm{kHz}$. The difference between valve positions in consecutive signal registrations was very small and the whole range contained 146 measurements. For better visibility, the presented plots contain only the part that contains the onset of unstable phenomena between halfopen valve to almost total closure. Values of TOA<4\% were not examined for safety reasons. In order to ensure disappearance of temporary pressure oscillations a settling time of $20 \mathrm{~s}$ was provided prior to each measurement. The conditions of the experiment were called "quasi-dynamic" contrary to dynamic tests conducted at variable throttling applied in various studies [22-24]. All signals were assumed to be deterministic and the Fourier transformation (by means of an FFT algorithm) was used to obtain their frequency spectra. The amplitude spectra (absolute values of the Fourier transforms) of the signals, acquired at different positions of the throttling valve, were presented in the form of 2D spectral maps obtained in a way presented in Fig. 3. Similar spectral maps were utilized by Raitor and Neise [25] for noise analysis and by Hellmich and Seume in the case of an axial high speed compressor [26]. This work, however, apart from applying the method to a different type of machine with different gauge locations also features by high resolution in the TOA that allows the identification of the moment of the first appearance of non-stable phenomena.

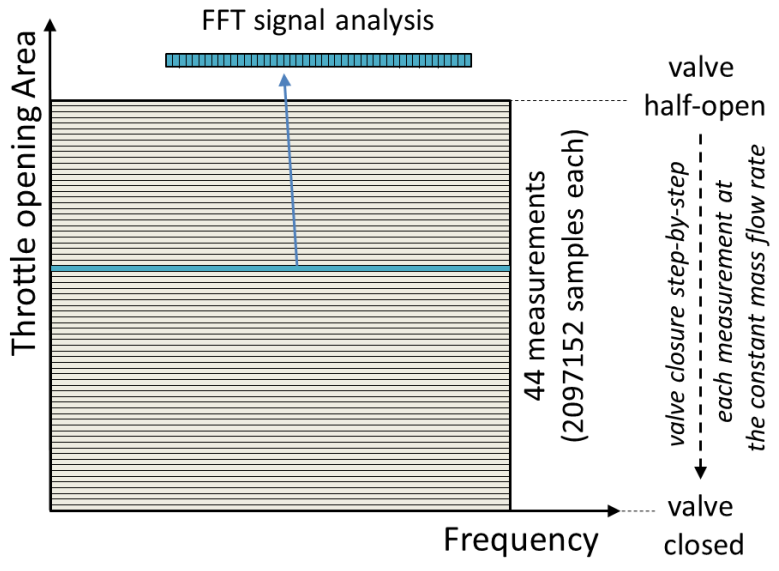

\section{Figure 3. Methodology of obtaining spectral maps in "quasi-dynamic" procedure.}

If the underlying assumption about the deterministic character of the signals had been false, the pressure spectra maps would have been disordered and without any regular patterns. In such a case, the assumption about deterministic signals wouldn't have been supported and a method of spectral density estimation of a random signal should have been applied. The obtained results have proven that the random components of the signals were rather weak. It can be explained by considering the fact that the signal gathering period was very long and included over 2000 rotations. In such a long period all the repeating phenomena were observed for several instances at least and the recorded signals are a good representation of the flow phenomena to be analyzed. On the other hand, the sampling frequency should be compared with the blade passing frequency $(B P F=2.3 \mathrm{kHz})$. The ratio 100/2 assured, that every significant flow structure was represented by several samples at least.

\section{RESULTS AND DISCUSSION}

The analysis given herein concerns the processed data received at each of the pressure tappings. The discussion is presented in the form of comparisons of pressure maps obtained at consecutive control points in the case of short and long pipes which will be referred to as SP and LP respectively. Table 1 summarises the highest amplitudes registered at all pressure tappings at surge $(T O A=4 \%)$.

\subsection{Stage inlet $\left(p_{\text {s-in }}\right)$}

Fig. 4 presents the spectral maps attained in the SP and LP configurations. In both cases low-frequency noise was observed at amplitudes of around $4 \mathrm{~Pa}(\mathrm{SP})$ and $16 \mathrm{~Pa}$ (LP). As it will be observed, this phenomenon was common for all gauges at all circumstances and was not associated with any particular phenomenon. Therefore this range was not considered in this study. 


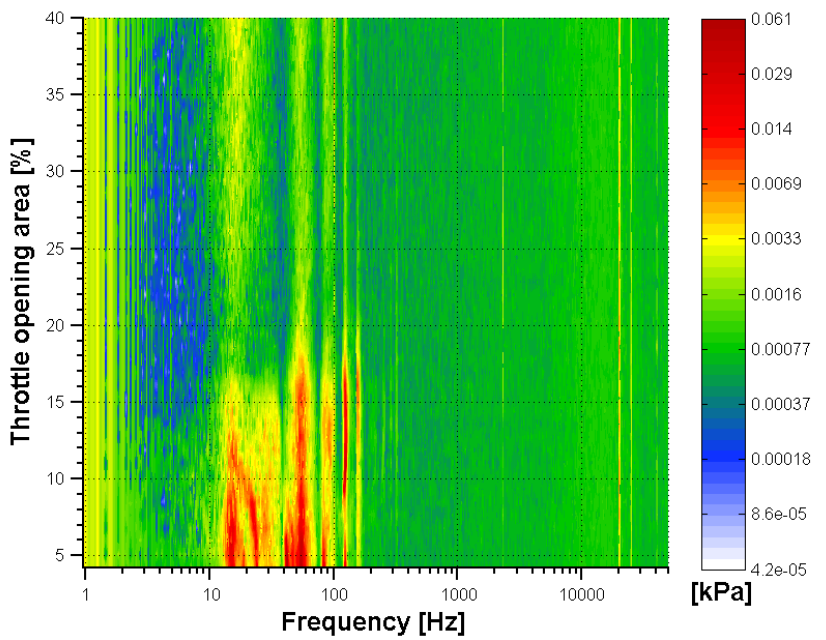

(a) Short pipe

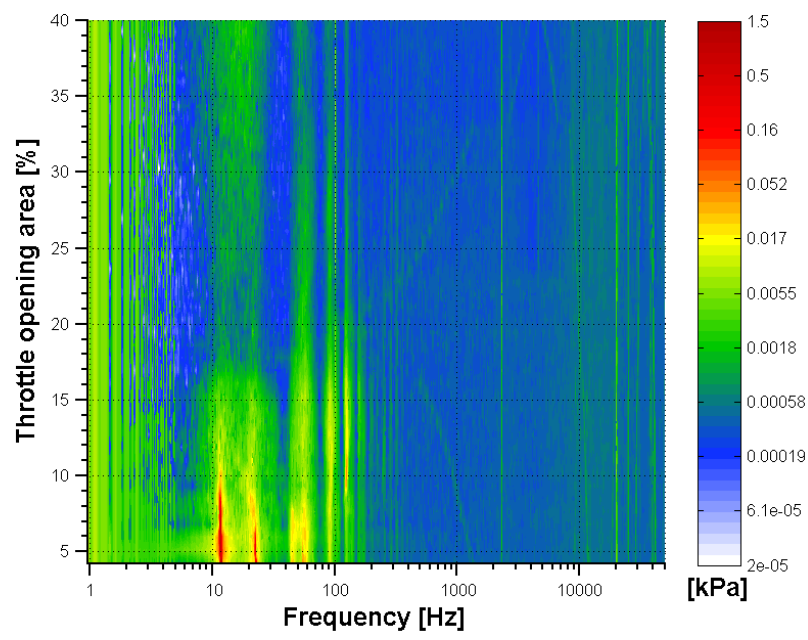

(b) Long pipe

Figure 4. Static pressure fluctuation $\Delta p$ spectral maps at the inlet $\left(p_{s-\text { in }}\right)$.

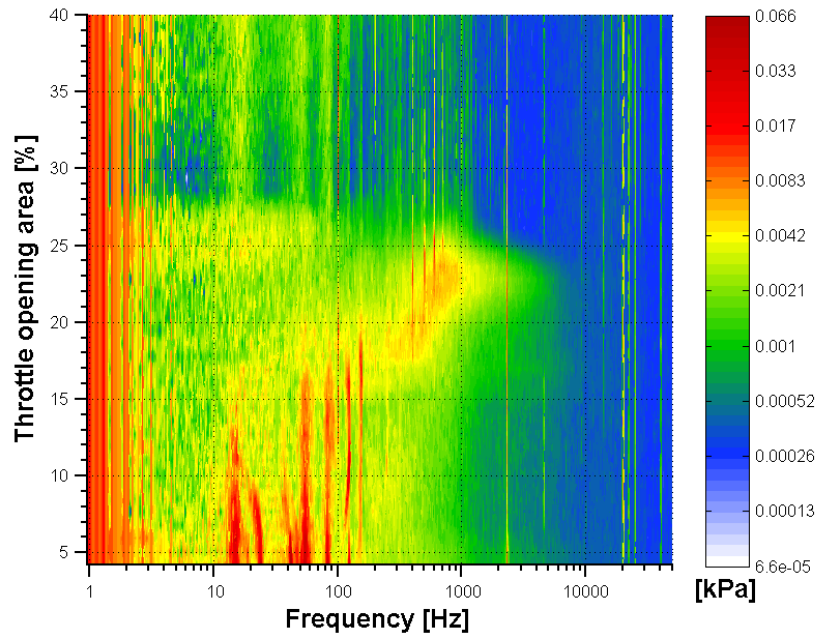

(a) Short pipe

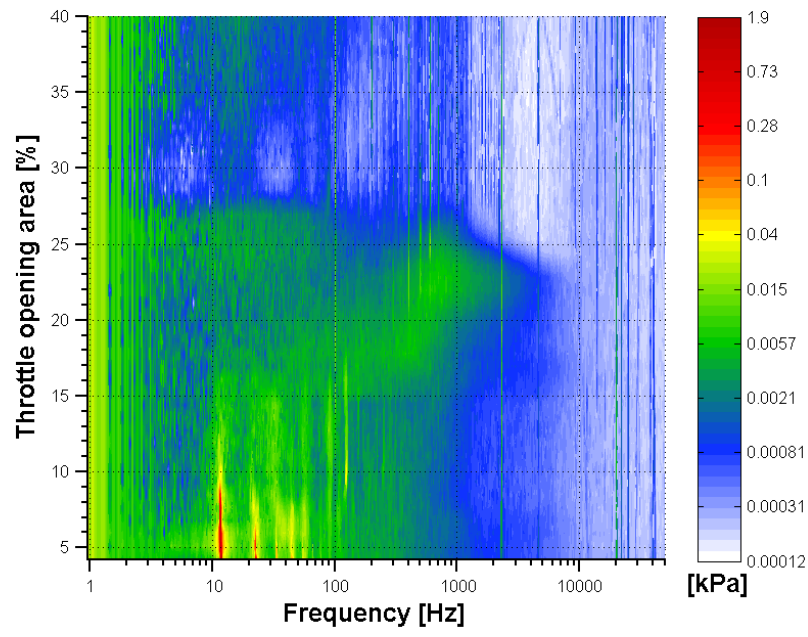

(b) Long pipe

Figure 5. Static pressure fluctuation $\Delta p$ spectral maps at impeller inlet $\left(p_{\text {s-imp } 1}\right)$.

At $T O A>27 \%$ a wide peak was observed at frequencies between $10 \mathrm{~Hz}$ and $20 \mathrm{~Hz}$. In this case, the fluctuation magnitude was almost independent of outlet volume and was close to $4 \mathrm{~Pa}$. As it can be observed in next sections, this region was less visible downstream as the flow entered the impeller. Similar peaks were visible between $40 \leq f \leq 100 \mathrm{~Hz}$. The peaks appeared to be relatively moderate (4-6 Pa) for the smaller volume and even less noticeable when the plenum volume was increased. At very high frequencies the noise level was slightly higher in the SP case.

In both cases, an increment in amplitudes by one order of magnitude was observed at around 17\% TOA. This region is henceforth referred to as the transient phase. At $T O A<10 \%$ the amplitude increased again by one (SP) or two (LP) orders of magnitude. This region is henceforth referred to as deep surge. At deep surge the fluctuations reached two major peaks:
- $f_{\mathrm{s}} \cong 14.1 \mathrm{~Hz} \quad(\mathrm{SP})$ and $f_{\mathrm{s}}^{\prime} \cong 10.8 \mathrm{~Hz}(\mathrm{LP})$;

- $f_{\mathrm{s}} \cong 41.1 \mathrm{~Hz}(\mathrm{SP})$ and $f_{\mathrm{s}}^{\prime} \cong 43.5 \mathrm{~Hz}(\mathrm{LP})$.

The highest pulsation magnitude in the LP case was equal to $1500 \mathrm{~Pa}$, which is 25 times higher than in the SP (see Table 1).

\subsection{Impeller inlet $\left(p_{\text {s-imp } 1}, L=-0.2\right)$}

Pressure fluctuation spectra at the impeller inlet shown in Fig. 5 look similar to the ones discussed above within the stable operational range $(T O A>27 \%)$. The difference was observed at $15 \leq T O A \leq 27 \%$ within a frequency range up to $f \leq 2000 \mathrm{~Hz}$, where high amplitude broadband noise appeared. The pulsations had a character of broadband noise without dominating peaks and were almost independent of plenum volume. As described in $[15,18]$ these instabilities were provoked by the inlet recirculation which was first discovered in centrifugal 


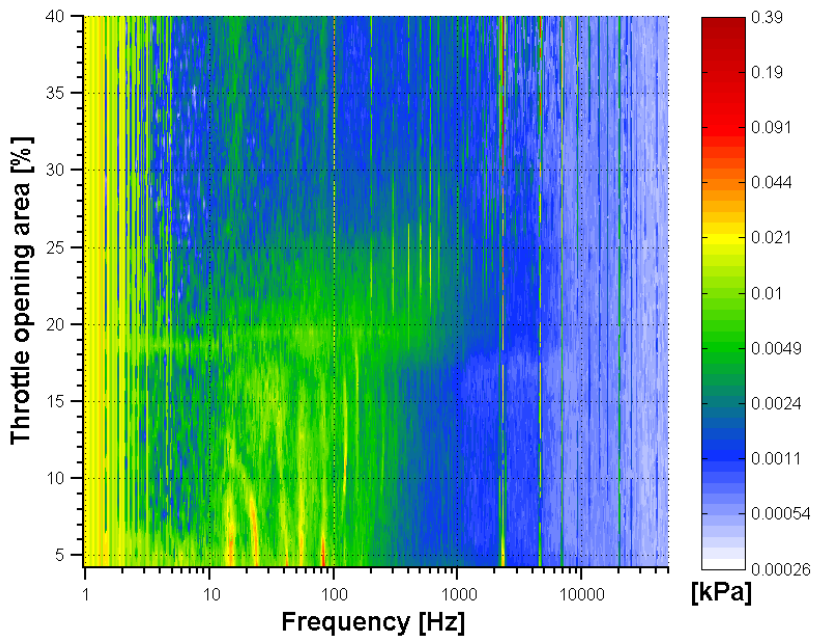

(a) Short pipe

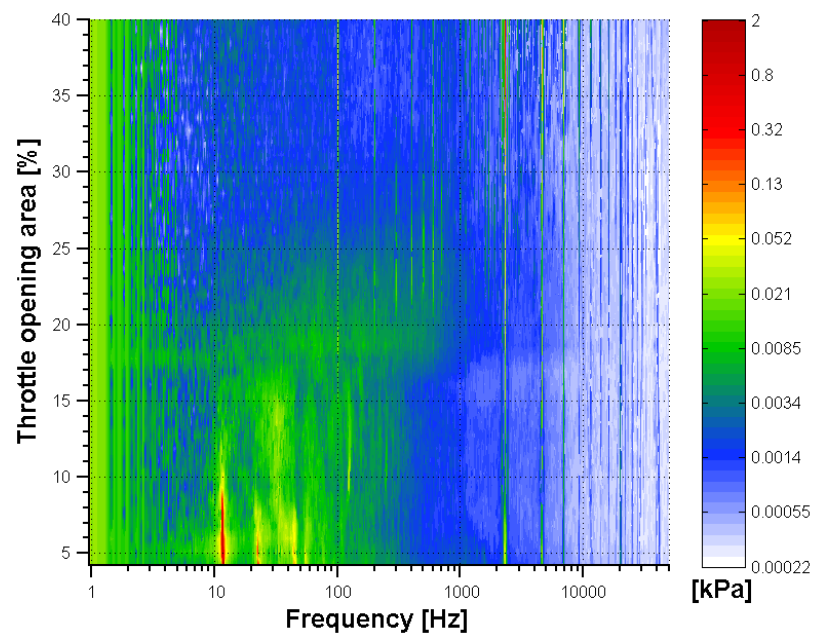

(b) Long pipe

Figure 6. Static pressure fluctuation $\Delta p$ spectral maps at impeller middle part $\left(p_{\text {s-imp } 2}\right)$.

pumps [19, 20]. Kryłłowicz [21] stated that the inlet recirculation was also characteristic for centrifugal compressor units with semi-open impellers. The phenomenon was described as a torus shaped vortex which initiated the stage unstable operation in the vicinity of impeller leading edge close to the shroud. The torus covered the whole circumference and its thickness was likely to grow with the mass flow decrease. As throttling increases, the torus gets disturbed by the flow oscillating in the axial direction (surge). It may also completely diminish or reduce its thickness if surge doesn't start [21]. As observed in Fig. 5 in this study inlet recirculation diminished in both outlet pipe configurations. Moreover, the moment of inlet recirculation onset and finish did not depend on plenum volume. The amplitude at surge in this region constituted $70 \mathrm{~Pa}$ in the SP case and $1900 \mathrm{~Pa}$ in the LP case. The ratio of surge dominating amplitudes had therefore increased to 27.1.

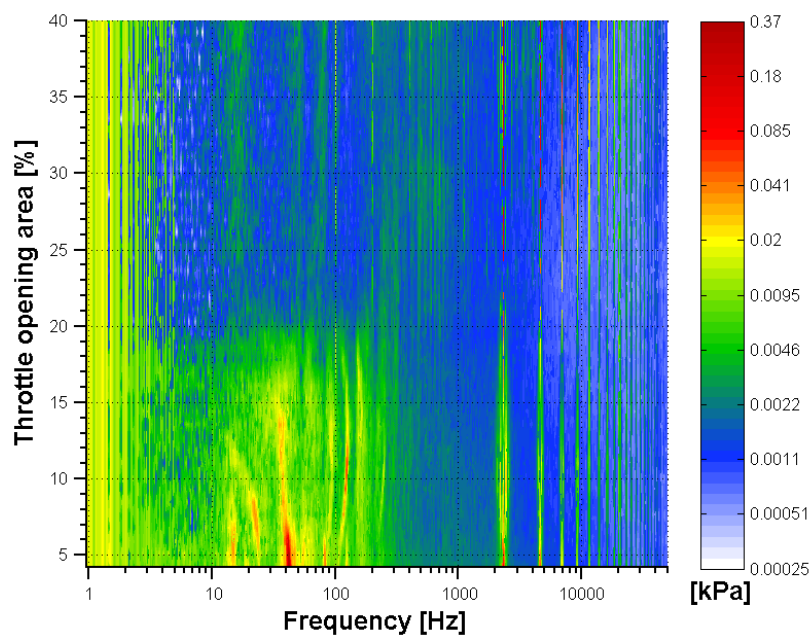

(a) Short pipe

\subsection{Impeller mid-chord $\left(p_{\text {s-imp2 }}, L=0.4\right)$}

Fig. 6 represents the spectral maps obtained at the midchord. The influence of inlet recirculation was still visible at this point at $15 \leq T O A \leq 27 \%$, however to a much smaller extent. It was observed as a smaller amplitude of the broadband noise and a smaller frequency range $100 \leq f \leq 1000 \mathrm{~Hz}$. This fact stays in agreement with the current state of the art saying that the spatial range of influence of inlet recirculation is very limited. In addition to that, the blade passing frequency (BPF) $f_{\mathrm{BPF}}=n z_{i m p}$ peaks of $2300 \mathrm{~Hz}, 4600 \mathrm{~Hz}, 6900 \mathrm{~Hz}$ etc. become visible, which wasn't observed earlier. The BPF amplitudes didn't show any dependency on the plenum volume and varied from $500 \mathrm{~Pa}$ to $1000 \mathrm{~Pa}$. Ultimately, the rotor frequency $f_{\text {rot }}$ and its modes were noticeable and also stayed independent of the outlet pipe length.

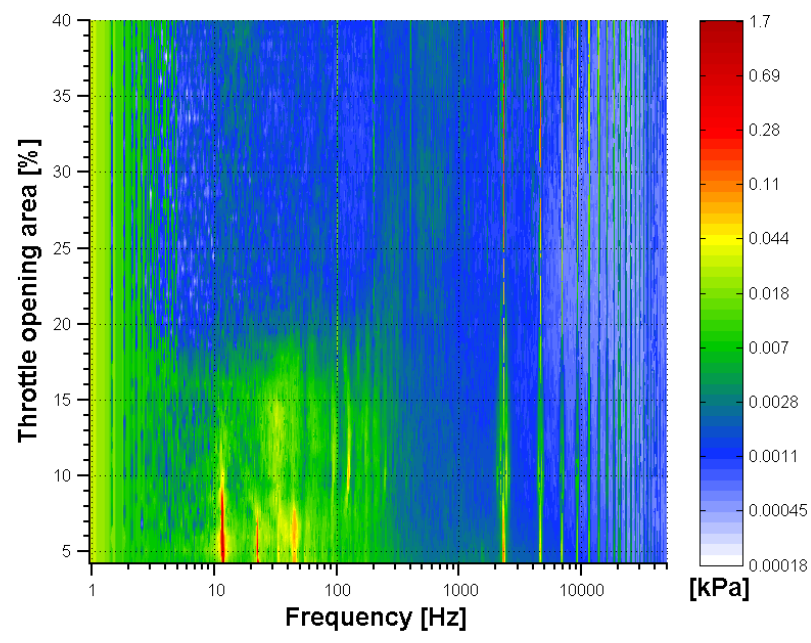

(b) Long pipe

Figure 7. Static pressure fluctuation $\Delta p$ spectral maps at impeller outlet ( $\left.p_{s-\text {-imp }}\right)$. 


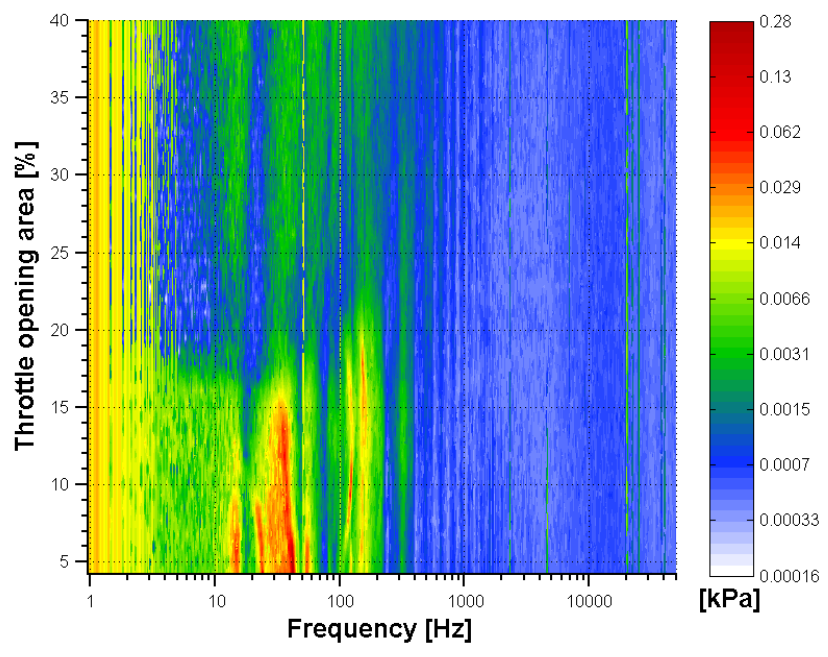

(a) Short pipe

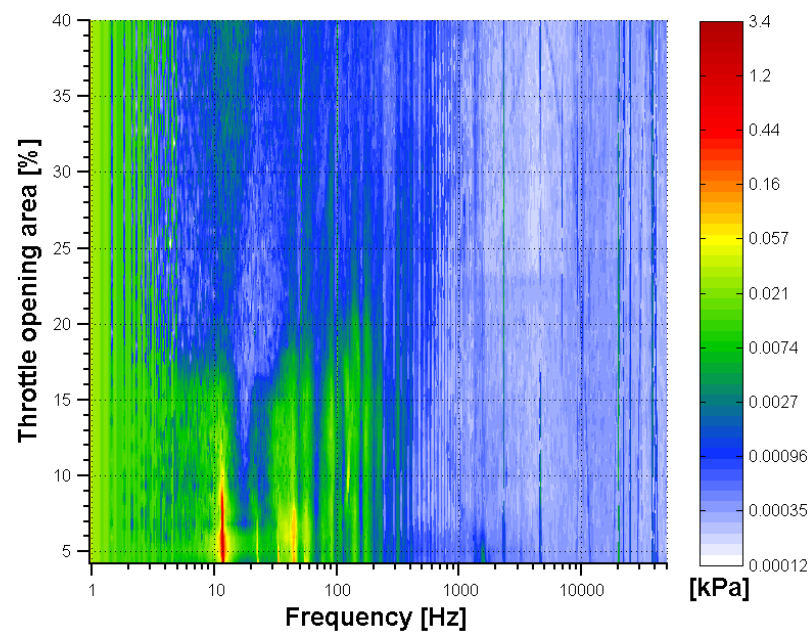

(b) Long pipe

Figure 8. Static pressure fluctuation $\Delta p$ spectral maps at the volute outlet ( $p_{\text {s-out }}$ ).

\subsection{Impeller outlet $\left(p_{\mathrm{s} \text { imp } 3}, 0.9 L_{\mathrm{m}}\right)$}

At impeller outlet (Fig. 7) the inlet recirculation was not observed. The amplitude peaks at TOA $<10 \%$ (surge) kept their corresponding frequencies. What is worth mentioning is that, the fourth $(9200 \mathrm{~Hz})$ and further $B P F$ modes were more explicitly visible than at the middle section of the impeller. The SP surge peak amplitude had grown to around $370 \mathrm{~Pa}$ which was the highest oscillation amplitude in this case (see Table 1). Compared to $p_{\text {s-imp2 }}$, it had risen around 7.5 times. In the LP case the oscillation amplitude maintained a high level at all gauges. This showed that the plenum volume influenced not only the frequency, but also the size of the region affected by flow oscillations which, in the case of the SP, was more concentrated downstream of the impeller (this issue is discussed in section 4).

\subsection{Volute outlet $\left(p_{\text {s-out }}\right)$}

The pressure pulsation pattern at the volute outlet in Fig. 8 appeared to be only slightly dependent on the network volume down to $T O A=27 \%$. As in previous cases, the fluctuations appeared to be stronger in the SP case. As the flow becomes unstable several significant differences in plenum response could have been declared.

Firstly, a fall in noise amplitude was observed within the region $18<f<20 \mathrm{~Hz}$ (SP). As the outlet pipe length was changed, the fall became more pronounced and settled down between $15 \mathrm{~Hz}$ and $30 \mathrm{~Hz}$ (LP).

The discrepancy in dominating surge amplitude noticed at the other pressure tappings stayed present at the machine outlet. The SP peak frequency was near to $42 \mathrm{~Hz}$; the magnitude was around $280 \mathrm{~Pa}$. In the LP case, the amplitude peak reached $3400 \mathrm{~Pa}$ and oscillated with a frequency of around $10.8 \mathrm{~Hz}$. The amplitude ratio equalled 12.1 which was higher compared to the gauge $p_{\mathrm{s} \_ \text {imp3 }}$. Contrary to SP case, in the instance of higher plenum
Table 1. Maximal peaks registered at the pressure tappings.

\begin{tabular}{|c|c|c|c|}
\hline & Short pipe & Long pipe & Ratio \\
\hline \multicolumn{4}{|c|}{ Frequency [Hz] } \\
\hline$f_{\mathrm{s}}$ & 41.1 & 10.8 & - \\
\hline \multicolumn{4}{|c|}{ Amplitude of pressure fluctuations [Pa] } \\
\hline$p_{\text {s-in }}$ & 60 & 1500 & 25.0 \\
\hline$p_{\text {s-imp1 }}$ & 70 & 1900 & 27.1 \\
\hline$p_{\text {s-imp2 }}$ & 90 & 2000 & 22.2 \\
\hline$p_{\text {s-imp3 }}$ & 370 & 1700 & 4.1 \\
\hline$p_{\text {s-out }}$ & 280 & 3400 & 12.1 \\
\hline
\end{tabular}

volume the highest oscillation amplitude was noted at $p_{\text {s-out }}$.

As the blade trailing edge wakes have already mixed inside the vaneless diffuser and volute, the BPF nodes were no longer present at this point. Some rotor rotational frequency modes were still visible, but all of them had negligible magnitudes and were irrelevant for the analysis.

\section{DOMINATING FREQUENCIES AT THE DEEP SURGE}

The aim of this section is to take a deeper insight into the blower surge regime spectral characteristics. Fig. 9 shows the amplitude-frequency maps of pressure signal recorded at $p_{\text {s-out }}(\mathrm{a}, \mathrm{b})$ and $p_{\mathrm{s} \_ \text {imp } 3}(\mathrm{c}, \mathrm{d})$ at deep surge $(\mathrm{TOA}=4 \%)$. One can observe that the amplitude of pressure pulsations reached its maximum either at frequency $f_{\mathrm{B}} \cong 42 \mathrm{~Hz}$ (SP, peak "B") or at $f_{\mathrm{A}} \cong 12 \mathrm{~Hz}$ ( $\mathrm{LP}$, peak "A") depending on the plenum size. Although it can be noted that peak A was also observed in SP case, and peak B was observed in LP case. 


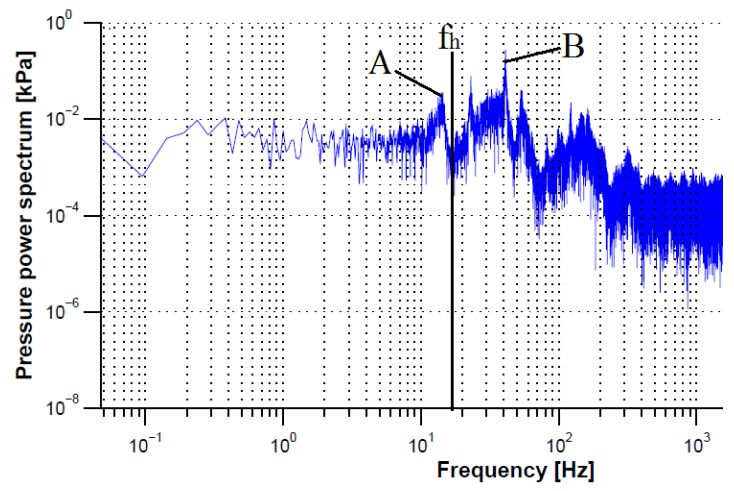

(a) Short pipe

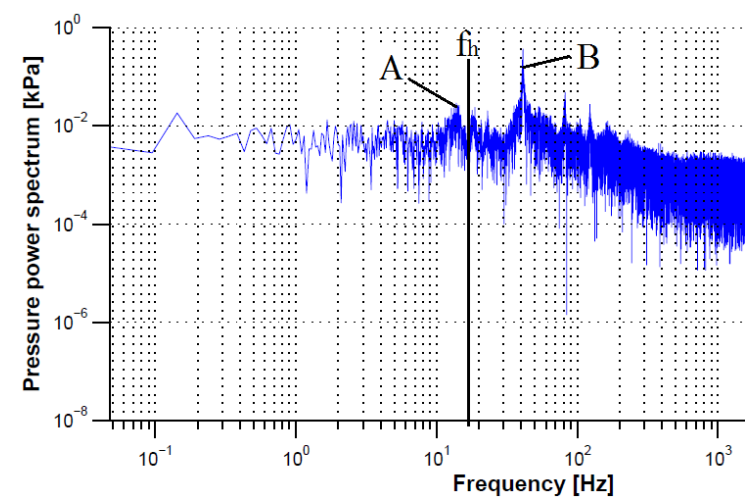

(c) Short pipe

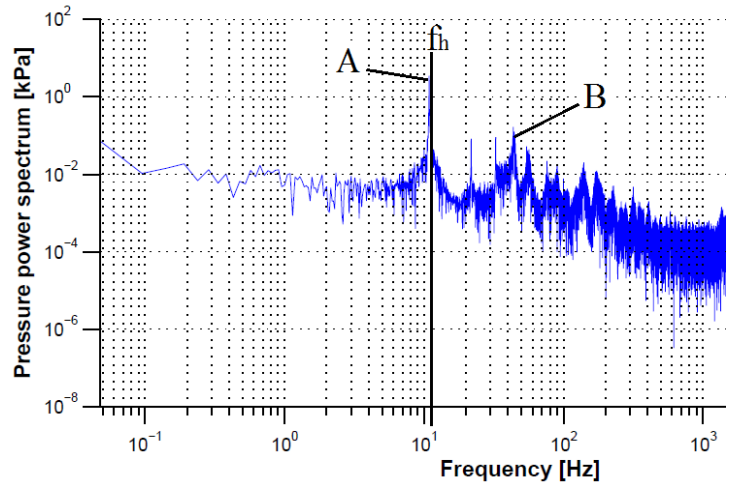

(b) Long pipe

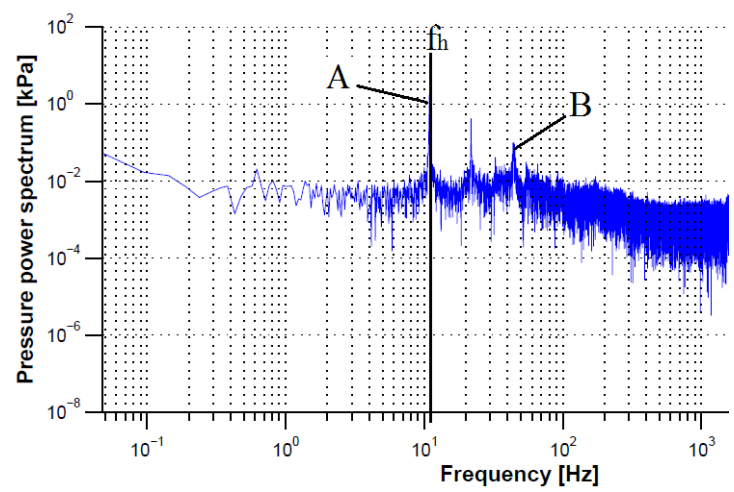

(d) Long pipe

Figure 9. Frequency spectra at the impeller outlet $p_{\text {s-out }}(\mathbf{a}, \mathbf{b})$ and volute outlet $p_{\text {s-imp3 }}(\mathbf{b}, \mathbf{c})$ at deep surge (TOA=4\%) and the value of Helmholtz frequency for this system.

As comes from the plots "a" and "c" (Fig. 9), the highest amplitude peak in a SP case was registered at impeller outlet $\left(p_{\text {s-imp3 }}\right)$. The "B" peak magnitude at this location constituted $\Delta p_{\mathrm{B}}=370 \mathrm{~Pa}$ (see Table 2), which was around 6 times higher than the identical peak amplitude at the compressor inlet $\left(p_{\text {s-in }}\right)$. This confirms that the oscillation "B" was not propagated throughout the whole system, but was localized mainly within diffuser and volute. Most probably, the peak was induced within the vaneless diffuser which is a known source of such unstable phenomena such as rotating stall [6,7]. The frequency of diffuser rotating stall is believed to be not higher than $0.22 f_{\text {rot }}$ [5-7]. Therefore in this case, the oscillations could have been associated with this structure containing two cells. This is supported by the fact, that in SP case, peak B was observed together with its subharmonic frequency $20.5 \mathrm{~Hz}$ characterized by slightly weaker amplitude.

A different trend was observed in the LP case where the maximal "A" peak magnitude was obtained at the volute outlet $\left(p_{\text {s-out }}\right)$. Here it constituted $\Delta p_{\mathrm{A}}=3400 \mathrm{~Pa}$ (see Table 2) which was 2.3 times higher than at the inlet $\left(p_{\text {s-in }}\right)$. This suggests propagation of this oscillation throughout the whole system. This feature is characteristic for surge $[1,6]$.
Table 2. Helmholtz resonance frequency versus surge frequency observed in the experiment

\begin{tabular}{|c|c|c|}
\hline & Short pipe & Long pipe \\
\hline \multicolumn{3}{|c|}{ Volume $\left[\mathrm{m}^{3}\right]$} \\
\hline $\mathrm{V}_{\mathrm{p}}$ & $4.35 \cdot 10^{-2}$ & $9.68 \cdot 10^{-2}$ \\
\hline \multicolumn{3}{|c|}{ Volute outlet $p_{\text {s-out }}$} \\
\hline $\mathrm{f}_{\mathrm{A}}, \mathrm{Hz}$ & 14.1 & 10.8 \\
\hline $\mathrm{f}_{\mathrm{h}}, \mathrm{Hz}$ & 17.1 & 11.5 \\
\hline$\Delta \mathrm{p}_{\mathrm{A}}, \mathrm{Pa}$ & 36 & 3400 \\
\hline$\frac{\Delta \mathrm{p}_{\mathrm{A}}}{\Delta \mathrm{p}_{\mathrm{s} \text {-in }}}$ & 1.57 & 2.27 \\
\hline \multicolumn{3}{|c|}{ Impeller outlet $p_{\text {s-imp3 }}$} \\
\hline $\mathrm{f}_{\mathrm{B}}, \mathrm{Hz}$ & 41.1 & 43.5 \\
\hline$\Delta \mathrm{p}_{\mathrm{B}}, \mathrm{Pa}$ & 370 & 100 \\
\hline$\frac{\Delta \mathrm{p}_{\mathrm{B}}}{\Delta \mathrm{p}_{\mathrm{s} \text {-in }}}$ & 6.07 & 3.45 \\
\hline
\end{tabular}

The $f_{\mathrm{A}}$ values were compared to the Helmholtz resonator frequencies $f_{\mathrm{h}}$ calculated for each plenum volume correspondingly (see Table 2). The sonic speed $a=\sqrt{k R T}$ was taken at ambient conditions $\left(k=1,4 ; R=287 \frac{\mathrm{J}}{\mathrm{kg} \cdot \mathrm{K}} ; T=293 K\right)$ and was equal to $a=340 \mathrm{~m} / \mathrm{s}$. A single blade passage area at the impeller outlet was used as the resonator inlet area 
$\left(A_{c}=6.76 \times 10^{-4} \mathrm{~m}^{2}\right)$ and an average meridional impeller channel length as its length $\left(L_{c}=1.56 \times 10^{-1} \mathrm{~m}\right)$.

Table 2 shows that the Helmholtz frequency is in a reasonable agreement with peak " $A$ " frequency with slight over prediction. In the case of a smaller plenum values differ by $20 \%$. As the outlet volume was increased, the relative difference dropped to $6 \%$. The over prediction can be coming from the fact, that the outlet valve was not fully closed and the actual volume of oscillating air was higher than the assumed plenum volume.

The Helmholtz resonator approach is based on rough simplifications and can be treated as a first approach to predict the dominating frequency of non-stable structures only. The real cases exhibit much more complicated spectra depending on the geometry of the diffuser, volute, plenum and the impeller. The Helmholtzian resonance may, however, co-exist with higher order oscillations and, in favourable circumstances, dominate the compressing system.

\section{CONCLUSIONS}

A single stage centrifugal blower was used to investigate the influence of outlet plenum volume on the pressure fluctuations. Kulite high frequency pressure transducers were installed at five control points along the flow path to record the signal. The pressure fluctuation spectra were analyzed in "quasi-dynamic" methodology and spectral maps were produced. The main conclusions are listed below:

1. Four stages of compressor operation were identified depending on the value of throttling: stable operation, inlet recirculation, transient stage and deep surge.

2. The moment of instability onset did not display dependency on plenum volume. This applied to all non-stable structures: inlet recirculation, transient stage and deep surge.

3. The inlet recirculation was recorded by gauges at the impeller inlet and less significantly at the impeller midchord. The spectral structure of this phenomenon didn't show sensitivity to the plenum volume.

4. A stronger surge pressure pulsation was diagnosed in the case of higher plenum volume. The pulsation was found to have a frequency very close to that of a Helmholtzian resonator. A Helmholtzian peak was also observed in the SP case, but was weaker than another peak present at higher frequency.

5. Highest pulsations in the SP case were registered at the impeller outlet, while in the LP case - within the plenum. This shows that these two peaks differ not only in frequency but also in localization of the source of fluctuations.

6. The oscillations in the LP case were noticeable at all pressure tappings, while in SP case, the oscillations were very weak at gauges located further from diffuser and volute. Therefore, the LP case was affected by strong axial oscillations influencing the whole machine. At a smaller plenum volume the oscillations had a more local character, with the source most likely located within the diffuser.

7. The BPF mode peaks were mainly visible at the impeller mid-chord, impeller outlet and were found to have amplitudes independent on the outlet volume.

\section{REFERENCES}

[1] Emmons, E. M., Pearson, C. E., Grant, H. P., 1955, "Compressor Surge and Stall Propagation", Transaction of the ASME 77, pp. 455-469.

[2] Eckardt, D., 1978, "Investigation of The Jet-Wake Flow of a Highly-Loaded Centrifugal Compressor Impeller", NASA Tech. Mem. 72232., 182 p.

[3] Hathaway, M.D., Wood, J.R., Wasserbauer, C.A., 1991, NASA Low-Speed Centrifugal Compressor for 3-D Viscous Code Assessment and Fundamental Flow Physics Research/ NASA Tech Mem. 103710, 14 p.

[4] Cumpsty, N. A., 1989, "Compressor Aerodynamics", Halsted Press.

[5] Pampreen, R., 1993, "Compressor Surge and Stall", Concepts Eti.

[6] Izmaylov, R. A., 2009, "Unsteady Flow Phenomena in Centrifugal Compressor: Rotating Stall and Beyond", 12th International Symposium on Unsteady Aerodynamics, Imperial College London.

[7] Frigne, P., V. D. Braembussche, R., 1984, "Distinction Between Different Types of Impeller and Diffuser Rotating Stall in a Centrifugal Compressor With Vaneless Diffuser", Journal of Engineering for Gas Turbines and Power, 106, pp. 468-474.

[8] Moore, F. K., Greitzer, E. M., 1986, "A Theory of Post-stall Transients in Axial Compression Systems: Part I - Development of Equations", Journal of Engineering for Gas Turbines and Power, 108, pp. 6876.

[9] Greitzer, E. M., Moore, F. K., 1986, "A Theory of Post-Stall Transients in Axial Compression Systems: Part II - Application", Journal of Engineering for Gas Turbines and Power, 108, pp. 231-239.

[10] Morini, M., Pinelli, M., Venturini, M., 2007, "Development of a One-Dimensional Modular Dynamic Model for the Simulation of Surge in Compression Systems", Journal of Turbomachinery, 129, pp. 437-447.

[11] Spakovszky, Z. S., 2004, "Backward Travelling Rotating Stall Waves in Centrifugal Compressors", Journal of Turbomachinery, 126, 1-12.

[12] Horodko, L., 2005, "Investigation of Centrifugal Compressor Surge with Wavelet Methods", 
Proceedings of 6th Conference on Turbomachinery Fluid Dynamics and Thermodynamics, France

[13] Fink, D. A., Cumpsty, N. A., Greitzer, E. M., 1992, "Surge Dynamics in a Free-Spool Centrifugal Compressor System", Journal of Turbomachinery, 114, pp. 321-332.

[14] Koyama, M., Komatsubara, Y., Tsujita, H., Mizuki, S., 1998, "Effect of Plenum Volume on Rotating Stall and Surge of Centrifugal Compressor", Proceedings of ISROMAC-7, Honolulu, Hawaii, pp. 1159-1167.

[15] G. Liśkiewicz, L. Horodko, M. Stickland, W. Kryłłowicz, 2014, Identication of Phenomena Preceding Blower Surge by Means of Pressure Spectral Maps, Experimental Thermal and Fluid Science, http://dx.doi.org/10.1016/j.expthermflusci.2014.01.002

[16] Magiera, R., Kryłłowicz W., 2006, "Wpływ Zastosowania Ciała Centralnego w Kierownicy Wlotowej na Strukturę Przepływu przed Kołem Wirnikowym Dmuchawy Promieniowej", (Polish) Cieplne Maszyny Przepływowy CMP 130, pp. 107116.

[17] Kuzmin, V. A., Khazhuev, V. N., "Measurement of Liquid or Gas Flow Velocity using Convergent Channels With a Witoszynski Profile", 1993, Measurement Techniques 36, pp. 288-296.

[18] McKee, R., Siebenaler, S., Deffenbaugh, D., 2004, Increased Flexibility of Turbocompressors in Natural Gas Transmission Through Direct Surge Control, Southwest Research Institute Technical Report.

[19] Breugelmans, F. A. E., 1982, "Peroration and Fluid Recirculation in the Suction Pipe of Centrifugal Pumps", Proceedings of the 11th Annual Turbomachinery Symposium, Texas A/M University, pp.165-180.

[20] Fraser, W. H., "Recirculation in Centrifugal Pumps", 1982, World Pumps.

[21] Kryłłowicz, W., 2001, Investigations of Unstable Operation of the Single-Stage Radial Compressor (in polish), Tech. Rep. 889, Technical University of Lodz.

[22] Lawless, P. B., and Fleeter, S., 1995, "Rotating stall acoustic signature in a Low-Speed Centrifugal Compressor. I: vaneless diffuser", Journal of turbomachinery, 117(1), pp. 87-96.

[23] Horodko, L., 2006, "Identification of rotating pressure waves in a centrifugal compressor diffuser by means of the wavelet cross-correlation", International Journal of Wavelets, Multiresolution and Information Processing, 4(02), pp. 373-382.

[24] Bulot, N., Ottavy, X., and Trebinjac, I, 2010, "Unsteady pressure measurements in a high-speed centrifugal compressor", Journal of Thermal Science, 19(1), 34-41.
[25] Till Raitor, Wolfgang Neise, 2008, "Sound generation in centrifugal compressors", Journal of Sound and Vibration, 314(3-5), pp. 738-756

[26]. Hellmich B., Seume J. R., 2008, "Causes of Acoustic Resonance in a High-Speed Axial Compressor", Journal of Turbomachinery", 130(3) 